\title{
A structured approach to strategic alignment between business and information technology objectives
}

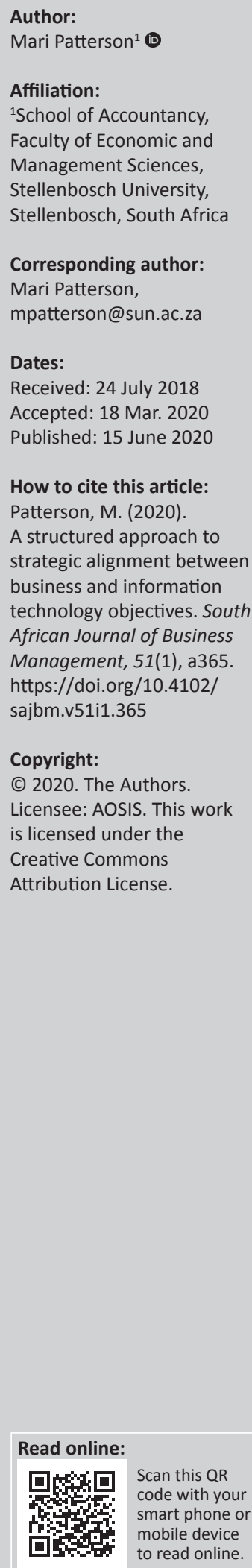

Purpose: Information Technology (IT) is developing at an accelerated rate, making it virtually impossible to separate business and IT strategies. Consequently, the IT strategy of an entity must be integrated with its overall business strategy in order for IT to add value to an entity. It is important that both senior management and IT specialists be involved in the design, implementation, running and revision of IT solutions in order for IT to assist in meeting the strategic objectives of the entity. Miscommunication between senior management and IT specialists is however a major contributing factor to IT projects failing to deliver the desired value. This concept is known as the 'IT gap'. The IT gap arises because there is a divergence in objectives between these two parties. The differences in objectives arises from the nature of their respective work and the tools they use. Management employs business model design tools (such as the Business Model Canvas), while IT management uses governance frameworks (such as the Control Objectives for Information and Related Technologies [COBIT]). In order for value to be generated, there needs to be alignment between these models and more importantly their objectives. The purpose of this study is to develop a comprehensive list of key driving forces of an entity, known as business imperatives, that can be used by senior management and IT specialists in an entity to ensure that the technology architecture of an entity is designed with the objective of supporting these business imperatives, thereby achieving alignment between the IT and business objectives of an entity.

Design/methodology/approach: In this conceptual study the Business Model Canvas was studied and its elements, representing generic business objectives, were converted into business imperatives that could be seen as essential to obtain a competitive advantage in various industries and environments. These business imperatives were mapped to the fifth edition of COBIT (COBIT 5) processes to identify those business imperatives that will be achieved by the IT department when implementing COBIT 5 and can therefore be seen as objectives for the IT department.

Findings/results: A comprehensive list of business imperatives was compiled. These business imperatives can be used to determine the design of the IT architecture of an entity, with the ultimate purpose of supporting the business objectives of the entity.

Practical implications: By using the comprehensive list of business imperatives identified in this study senior management and IT specialists can work together to ensure that the technology architecture of an entity is designed with the objective of supporting the business imperatives in order to ultimately achieve alignment between the IT and business objectives of an entity.

Originality/value: While previous studies primarily focussed on adapting business models to incorporate rapidly evolving technology, this study focussed on the manner in which technology architecture can be designed in order to support the business objectives of an entity.

Keywords: corporate governance; IT governance; strategic alignment; business objectives; IT objectives; business-IT alignment; IT gap.

\section{Introduction}

Technological change has given rise to new ways in which entities can create, deliver and capture value to customers in order to generate revenue, in other words new business models (Osterwalder, 2004, p. 15; Osterwalder \& Pigneur, 2005, p. 13). It is important for entities to stay up to date with new information technologies and trends. At the same time, in order for Information Technology (IT) to add value to an entity, it is essential to achieve strategic alignment between the IT and business strategies of an entity (Institute of Directors Southern Africa, 2016, p. 62; Juiz, Gómez, \& Barceló, 2012, p. 70; Wilkin \& Chenhall, 2010, p. 113). 
The fourth edition of the King Report on Corporate Governance for South Africa (King IV) principle 12 requires, amongst other things, that IT should add value to the entity through investments in both information and technology and that alignment between an entity's business and IT strategies (business-IT alignment) should be enabled at two levels. Firstly, entities should capitalise on technological developments by incorporating it into the business model of the entity (Institute of Directors Southern Africa, 2016, p. 63). In the second place, entities' technology architecture should enable the achievement of their overall business strategy (Institute of Directors Southern Africa, 2016, p. 63).

Extensive prior research has been conducted to determine the way in which rapidly evolving technology and the internet can be incorporated into business models. Osterwalder and Pigneur (2005, pp. 6-7) were pioneers in defining the concept of the business model and concluded that a close correlation exists between the prominence of the concept of business models and the introduction of the internet into the business sphere towards the late 1990s. Teece (2010, p. 173) analysed the importance of business models and found that, in order to benefit from innovation, attention needs to be paid to business model design and the impact of, amongst other factors, evolving technology on the design of business models. During subsequent research conducted, Osterwalder and Pigneur (2013, p. 238) remarked that IT can assist researchers in the strategic management field to investigate the process of generating business models.

In order to design an entity's technology architecture in alignment with its business strategy, entities should also consider how the business model influences the IT-related decisions made in entities (Clauss, 2017, p. 392; De Haes \& Van Grembergen, 2009, p. 124; Institute of Directors Southern Africa, 2016, p. 63). Both senior management of the business and IT specialists should be engaged in the design, implementation, running and revision of IT solutions (Bowen, Cheung, \& Rohde, 2007, p. 191; Goosen, 2012, pp. 14-15; Rudman, 2011, p. 37). This will enable the achievement of business-IT alignment, as required by King IV (Institute of Directors Southern Africa, 2016, pp. 62-63). The business side of an entity consists of senior management responsible for designing and implementing the business objectives and implementing the structures, processes and mechanisms to address IT governance (Institute of Directors Southern Africa, 2009, p. 83). Information Technology specialists represent the senior management of the IT department of the entity responsible for implementing IT solutions and control techniques on a component level, in order to achieve IT governance objectives (Goosen, 2012, pp. 14-15; Rudman, 2011, p. 37).

Despite the emphasis King IV places on the importance of alignment between the IT department and business, miscommunication between senior management and IT specialists often take place (Rudman, 2011, p. 37-39). This statement is supported by a McKinsey\&Company survey that indicated that IT managers are not collaborating with senior management and as a result the IT department does not fully support the overall business strategy (Khan, Reynolds, \& Schrey, 2016). The vast majority of respondents of this survey, however, agree that IT should play a partner role in the business and that entities whose IT departments are actively involved in the overall business strategy of the entity perform its core services far better than entities whose IT departments function in isolation (Khan et al., 2016). Furthermore, the findings for the fourth successive survey indicate a major gap between the way in which senior management and the IT function view the top priorities of the IT function (Khan et al., 2016). For the purpose of this study, this will be referred to as the 'IT gap'. As a result of the IT gap, entities currently follow an unstructured approach towards the implementation of IT solutions. The IT gap arises because there is a divergence in objectives between senior management and the IT function. The differences in objectives arise from the nature of their respective work and the tools they use. Management employs business model design tools (such as the Business Model Canvas), while IT management uses governance frameworks (such as the Control Objectives for Information and Related Technologies [COBIT]). In order for value to be generated, there is a need for a tool, framework or approach that will help to align these models.

\section{Research problem, objective and motivation}

Even though extensive research has been conducted on the manner in which technology can be incorporated into the design of business models, research relating to the design of technology architecture in line with the unique business models of entities, which should enable the achievement of an entity's overall business strategies (Boshoff, 2014), is not readily available. Previous studies by, inter alia, Goosen and Rudman (2013) and Smit (2009) attempted to develop business imperatives that can be used as IT objectives. However, these studies were not complete since they were not linked to established models or frameworks and were not grounded in theory. This study proposes to address this gap in research by developing a comprehensive list of business imperatives that can be used by senior management and IT specialists by making use of two theoretical models.

The board of directors are responsible for the implementation of the entities' overall strategies, whether it be business strategies or IT strategies. Generic business model design tools are available to assist senior management (or business) in formulating its business objectives, which must be achieved through the execution of business and IT strategies. King IV places the responsibility of alignment between the business and IT objectives of an entity on the board of directors (Institute of Directors Southern Africa, 2016, p. 63). The implementation of effective technology and information management should, however, be delegated to management (Institute of Directors Southern Africa, 2016, p. 62). An entity's strategic business objectives are achieved by means of both the basic business assumptions and business 
imperatives (Boshoff, 2014). Basic business assumptions represent generic objectives that are not unique to specific entities (Boshoff, 2014) and the implementation of basic IT solutions and internal controls are sufficient to govern these basic business assumptions (Goosen \& Rudman, 2013, p. 95). This does not represent business-IT alignment and the IT gap can only be bridged by aligning business imperatives, which are unique to each entity, with the technology architecture of an entity (Boshoff, 2014). Therefore, the business objectives derived from business model design tools must further be converted into business imperatives and objectives for the IT department in order for IT managers to implement the appropriate IT strategy that will result in the implementation of the appropriate technology architecture and for business and IT managers to work towards a common goal. Figure 1 illustrates the problem statement and the objective of the study.

The objective of this study is to develop a comprehensive list of business imperatives that can be used by senior management and IT specialists in an entity to design technology architecture in line with an entity's business objectives. The alignment of technology architecture with business objective will take place through the IT objectives. Consequently, the problem statement addressed in this paper is the misalignment between the business and IT objectives of entities. It is largely caused by miscommunication between senior management and IT specialists; and misalignment of priorities and a divergence of objectives.

The output of this research is of value to management charged with the responsibility of executing the alignment between the technology architecture and business objectives of an entity (Institute of Directors Southern Africa, 2016, p. 63). The comprehensive list of business imperatives that can be customised by management to an entity's unique context will improve alignment between the business and IT objectives of an entity. As a by-product, the output of this research will include structured guidance that can be used to improve communication between senior management and IT specialists. Furthermore, entities will also be provided with a

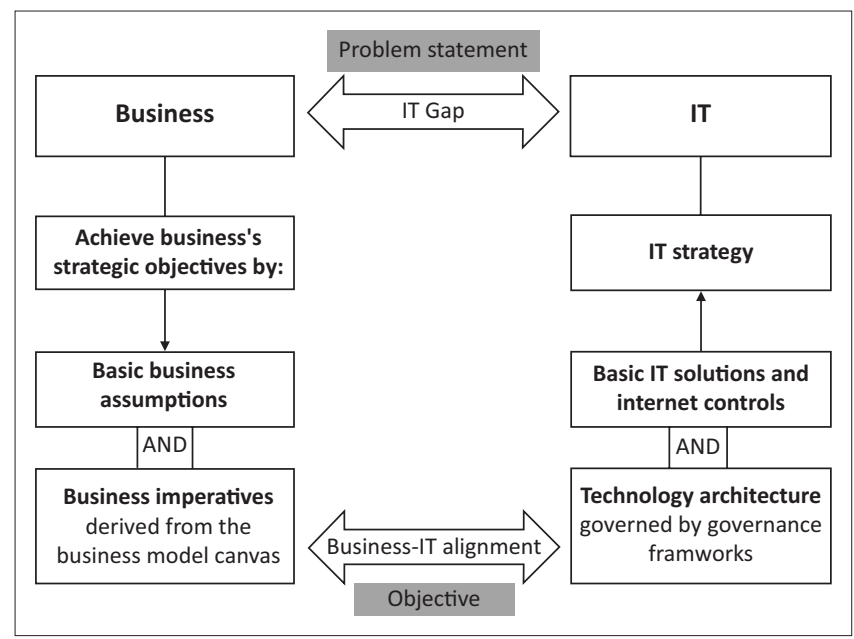

IT, Information Technology.

FIGURE 1: Problem statement and objective. tool that can be used to evaluate whether its current technology architecture supports its business objectives.

With the growing importance of IT in businesses, the research adds to the growing body of interdisciplinary research (Bishop, 2018; Enslin, 2012; Kruger, 2012; Sahd \& Rudman, 2017) in the field of Corporate Governance and IT.

\section{Methodology}

In order to provide management with a comprehensive list of business imperatives a qualitative study grounded in theory was conducted. The study commenced with a systematic literature review to gain an understanding of literature about business models and how they are supported by IT strategies, governance and the impact of technology architecture. Literature was also reviewed around the topic of business-IT alignment. As suggested by Sylvester, Tate and Johnstone (2011, pp. 1203-1204), initial searches relating to the broad concepts addressed by the study were conducted. During the mapping stage the focus of the searches were narrowed to yield more refined results. During the appraisal stage 108 sources were read in full and the most prominent concepts were grouped together. The analysis of the various texts during the synthesis stage resulted in a structured document in which the key theoretical concepts could be understood. Once the key theoretical concepts were understood, a business model design tool and a governance framework was selected. The motivation therefor are discussed in the following section.

Business model design tools are available to determine the business objectives of an entity. For the purpose of this study, these business objectives were converted into objectives for the IT department in the form of business imperatives. These can be used to avoid miscommunication between senior management and IT specialists to close the IT gap.

In order to compile a comprehensive list of business imperatives and provide management with guidance on the design of its technology architecture in line with its business imperatives, the following steps were followed:

1. The Business Model Generation (Osterwalder, Pigneur and Clark, 2010), a book which sets out the elements of the Business Model Canvas, a tool designed by Osterwalder, Pigneur and Clark (2010) that can be used to describe the elements of an entity's business model, was studied in detail. Since the Business Model Canvas only highlights broad principles, its building blocks were converted into a list of potential business imperatives that serve as the key driving forces of an entity. The detailed descriptions of the business imperatives identified during the systematic literature review (discussed above) were used to expand the definitions of the building blocks of the Business Model Canvas in more detail and with an IT focus. This also serves to identify business imperatives not identified by previous authors. Table 1-A1, included in Appendix 1, contains the conversion of the building blocks into the detailed business imperatives. 
2. The business imperatives were mapped against the enabling processes of COBIT 5. This was done to identify those business imperatives which are achieved when the COBIT processes are effectively implemented and therefore can be used to bridge the IT gap.

The business imperatives and the mapping to the COBIT enabling processes relevant to an entity could be used by senior management and IT specialists as a basis of discussion to determine the technology architecture required to give effect to the business imperatives of the entity (refer to the 'Practical implication for management' section). This improved communication will enhance alignment between the business and IT objectives of an entity (Figure 2).

As previously noted, previous researchers did not create a complete list of business imperatives. Validity and rigour are added to qualitative research by anchoring research in theory, a model or a framework. Therefore, academic rigour is added to this research by the use of two established models and as such is grounded in management theory.

The use of established models and frameworks also ensure the completeness of the business imperatives identified. Using the comprehensive list of business imperatives improves business-IT alignment. As Rajcoomar (2017:227) argued, the problem with research not grounded in management theory and guides developed by professional bodies is that the methodology it employs is in most cases not scientific methods, and as such may not be complete.

\section{Concepts underlying this research}

Before a comprehensive list of business imperatives can be developed, it is necessary to discuss the core concepts underlying this research. This section commences by creating

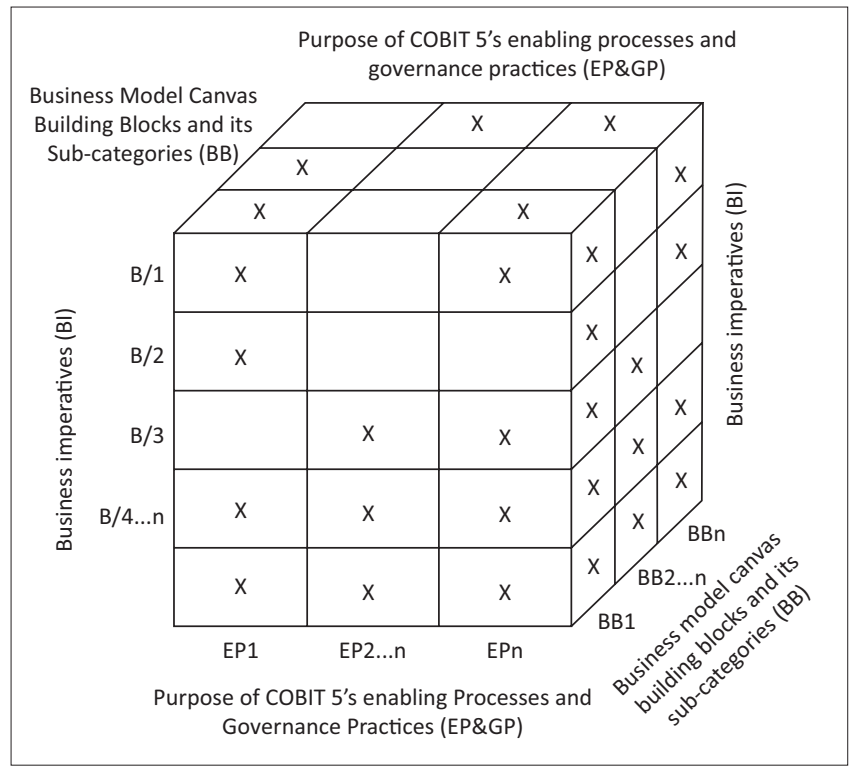

FIGURE 2: Identification of business imperatives that serve as both business (through Business Model Canvas building blocks) and IT objectives (through the COBIT enabling processes). a common understanding for the need to comprehend business models and governance frameworks, followed by a discussion on the need for alignment.

Basic business assumptions relate to the way in which an entity's operations are managed (Boshoff, 2014). Its implementation is essential in order for an entity to perform its basic day-to-day tasks efficiently and effectively in its specific business environment (Boshoff, 2014; Goosen \& Rudman, 2013, p. 95). Basic business assumptions are expected to be established in every entity and is not unique to specific entities or industries (Boshoff, 2014). Examples of basic business assumptions include, inter alia, that all entities are profit orientated, transact across all business processes, comply with general laws and regulations applicable to all entities, and consider cash flow and business continuity to be of critical importance (Boshoff, 2014; Goosen \& Rudman, 2013, p. 95). Basic IT solutions and internal controls are implemented in order to govern basic business assumptions (Goosen \& Rudman, 2013, p. 95). This, however, does not constitute business-IT alignment (Boshoff, 2014).

Business imperatives expand beyond the basic business assumptions and are those essential driving forces which need to be implemented in an entity and executed extraordinarily well for an entity to meet its strategic objectives (Boshoff, 2014). Business imperatives act as the key driving forces of an entity and the successful execution thereof will give the entity a competitive advantage in its specific environment (Boshoff, 2014). Business imperatives are therefore influenced by the context of an entity and determines the technology architecture which has to be governed (Boshoff, 2014).

The context of an organisation consists of internal factors relevant to an entity, as well as external forces (Boshoff, 2014). The internal factors can be summarised by its business model, which is in turn continually influenced by ever-changing external forces such as competition, social, legal or technological changes surrounding an entity, making each entity's business model unique (Clauss, 2017, p. 387; Osterwalder, 2004, p. 16). A business model is a theoretical tool which contains the elements of an entity and the relationships between these elements (Osterwalder et al., 2010, pp. 15-19). It provides the business context and mechanisms on how to achieve the entity's strategic objectives (Osterwalder, 2004, p. 14) and ultimately represents an entity's unique money-earning logic in the form of its customer relationships, value propositions and value networks (Osterwalder, 2004, p. 15; Osterwalder \& Pigneur, 2005, p. 13; Teece, 2010, p. 174).

Spieth, Schneckenberg and Ricart (2014, p. 243) as well as Chesbrough (2010, p. 359) view the Business Model Canvas developed by Alexander Osterwalder as a popular and rigorous business model design tool. Clauss (2017, p. 387) studied 19 sources containing 16 different conceptualisations of business models and business model innovation. He found 
that the components of the business models investigated can be grouped into three categories, namely value creation, value capture and value proposition. The nine building blocks of the Business Model Canvas address all three of these categories (Clauss, 2017, p. 387; Osterwalder et al., 2010, pp. 16-17).

Osterwalder (2004, p. 16) describes the business model's position in the entity as a theoretical link between business strategy, information and communication technology and business organisation. Business models can therefore be used to ensure a shared understanding of these three aspects by all parties involved, thereby ensuring that IT solutions are implemented in alignment with the business strategy (Osterwalder, 2004, p. 16). The effectiveness of IT solutions is, however, not guaranteed upon implementation and is greatly dependent on well-implemented IT governance structures (Bin-Abbas \& Bakry, 2014, p. 261; Wu, Straub, \& Liang, 2015, p. 498). IT governance is of critical importance to ensure that IT solutions implemented deliver the intended value to an entity and to ensure that IT supports an entity's strategies and objectives (De Haes \& Van Grembergen, 2009, p. 135; IT Governance Institute [ITGI], 2003, p. 10; Juiz \& Toomey, 2015, p. 59; Wu et al., 2015, p. 498). One way of achieving effective IT governance, as required by King IV (Institute of Directors Southern Africa, 2016, p. 62) is by implementing an IT governance framework. There are many IT governance frameworks such as, inter alia, PRINCE2 (Projects In Controlled Environments), ITIL (Information Technology Infrastructure Library) and COSO (the Committee of Sponsoring Organizations of the Treadway Commission), each with a different purpose. Control Objectives for Information and Related Technologies is a well-known IT governance framework which incorporates the principles of various other IT standards, including ITIL, ISO/IEC 38500, ISO 17799 and Capability Maturity Model Integration (Joshi, Bollen, Hassink, De Haes, \& Van Grembergen, 2018, p. 369).

The implementation of COBIT as an IT governance framework assists entities in achieving IT governance objectives and it plays a critical role in aligning business and IT objectives (De Haes, Van Grembergen, \& Debreceny, 2013, p. 312; Morales, 2014). By means of a thorough investigation of the COBIT 5 toolkit (ISACA, 2013), it is clear that COBIT 5 highlights certain business objectives which should be supported by IT in such a way that the entity ultimately extracts maximum value from IT in the most cost-effective manner. COBIT 5 highlights the purpose of its enabling processes in describing the goals that will be achieved when implementing these enabling processes and their underlying governance practices. The purpose of the enabling processes and governance practices can be aligned with the business imperatives identified for the purpose of this study. Successful alignment will identify the business imperatives that serve as both business objectives and objectives for the IT department of an entity and could act as the basis to bridge the IT gap in order to ultimately achieve alignment between business and IT at the technology architecture level.
King IV requires alignment between IT and the strategic and operational objectives of the entity (Institute of Directors Southern Africa, 2016, p. 63). Strategic alignment, i.e. the alignment between business and IT objectives, is one of the focus areas of IT governance (ITGI, 2008, p. 32) and can, in fact, be seen as the key to the achievement of IT governance (ITGI, 2003, p. 22; Wilkin \& Chenhall, 2010, p. 107). Strategic alignment will enable an entity to extract the desired value from their IT-related investments (Juiz et al., 2012, p. 70; Teece, 2010, p. 186; Wilkin \& Chenhall, 2010, p. 113). The IT Governance Institute (ITGI) (2003, p. 22) claims that businessIT alignment cannot be separated from the mere concept of IT strategy as it needs to support the overall strategy of the entity.

In order to successfully determine the way in which the technology architecture of an entity should be designed in order to enable the achievement of the entity's overall business objectives, the business objectives need to be converted into objectives for the IT department (Wu et al., 2015 , p. 504). These objectives should then form the basis of the IT strategy in order to facilitate successful alignment with the business strategy (Wu et al., 2015, p. 504). In order to successfully execute this process, clear communication between senior management and IT specialists is needed. However, miscommunication often occurs between senior management and IT specialists as a result of IT specialists' lack of understanding of the business objectives and the importance of IT governance and senior management's lack of understanding of IT (Goosen \& Rudman, 2013, p. 94; Osterwalder, 2004, p. 16; Rudman, 2011, p. 37). Identifying a comprehensive list of business imperatives relevant to an entity and determining how the technology architecture of an entity can be adapted to support these business imperatives will facilitate communication between senior management and IT specialists (Boshoff, 2014).

\section{Findings}

In order to create a comprehensive list of business imperatives that can be used as both business objectives and objectives for the IT department, generic business objectives derived from the Business Model Canvas were converted into objectives for the IT department. These business imperatives were then mapped against COBIT 5 in order to identify the business imperatives that will be enabled by the implementation of COBIT 5.

\section{Redefining Business Model Canvas building blocks to business imperatives}

The Business Model Canvas was studied to identify generic business objectives relevant to entities. These business objectives were converted into potential business imperatives in Table 1-A1, included in Appendix 1. From the systematic literature review twenty nine potential business imperatives were identified. The previous studies that attempted to identify business imperatives did not identify all the business imperatives, nor did they do so in a comprehensive manner 
linking the business imperatives to a theoretical model or framework.

The business imperatives (BI1 - BI29) contained in Table 1-A1, included in Appendix 1 can be further explained as follows:

- High throughput (BI1): In a mass market environment, for example, high throughput of products or services is essential (Boshoff, 2014).

- Customer centric (BI2): Entities look towards its customers in order to determine how its products should be developed or its services adapted (Boshoff, 2014; Brown, 2012). One way of achieving this is through targeted marketing towards customers, addressing their specific requirements (West, Ford, \& Ibrahim, 2015, p. 152) and potentially customising products or services to meet customers' needs (Osterwalder et al., 2010, p. 23). Educating customers, and thereby influencing their decisions, can be equally as important as receiving information from customers (Schrage, 2015).

- Low costs (BI3): Reducing operational and/or product costs can lead to a bigger profit margin (Boshoff, 2014; Drury, 2015, p. 13; Osterwalder et al., 2010, p. 25, 41) or products and services can be delivered at a lower cost than those of an entity's competitors (Kark, White, \& Briggs, 2015, p. 53; Osterwalder et al., 2010, p. 24). This makes products or services more accessible to the client base (Osterwalder et al., 2010, p. 25).

- Diverse products or lines of business (BI4): Certain entities are dependent on various income streams from diverse customer segments (Osterwalder et al., 2010, p. 21) in order to remain profitable, e.g. those who provide seasonal products or services and entities who provide products at a minimal cost or no profit, while providing additional complimentary products or services that are more profitable (Boshoff, 2014).

- Productivity and efficiency (BI5): Certain entities, for example those in the manufacturing industry, have to manage their operations in a productive and efficient manner (Goosen \& Rudman, 2013, p. 98) while Osterwalder et al. (2010, p. 35) states that simply assisting clients in 'getting the job done' can be an important part of an entity's business model.

- Reduction of delivery / cycle time (BI6): Entities need to minimise the time from the development phase of a new product to delivering it to the market, and reduce the time spent on non-value adding activities, to ensure availability of products (Drury, 2015, p. 14, 569).

- Product centric (BI7): Entities focus on the capabilities, skills and available resources within the entity to determine how its products or services should be developed (Boshoff, 2014; Brown, 2012).

- Innovation (BI8): Entities striving to be innovative leaders (also referred to as first movers) should be the first to, amongst other things, produce new products, deliver innovative, new services, employ certain processes or develop specific standards (Goosen \&
Rudman, 2013, p. 97; Kim, 2012, p. 142; Osterwalder et al., 2010, p. 23; Smit, 2009, p. 10).

- Fast follower (BI9): According to Kim (2012, p. 142) the profit-making strategy of a fast follower is to utilise the products, services, standards or processes developed by first movers in order to gain benefits from it. According to Snow, as cited by Seave (2014), fast followers experience an average failure rate of $8 \%$ compared to a failure rate of $47 \%$ experienced by first movers, largely as a result of first movers experiencing a lot of difficulties which fast followers can learn from.

- Rapid adaptability (BI10): Entities, as well as its employees, need to be increasingly resourceful, adaptable and tolerant of uncertainty in order to function at an optimum level in today's rapidly changing environments (Pulakos, Arad, Donovan, \& Plamondon, 2000, p. 612).

- Distributed branches and processes (BI11): Having multiple branches in order to reach a wider customer base, possibly distributed over a wide geographical area, is of critical importance to some entities, for example retail outlets (Boshoff, 2014). This could include an entity's own stores or partner stores and other channels, like partner-owned websites (Osterwalder et al., 2010, p. 27). The internet has enabled all entities to sell their products over a wide geographical area (Boshoff, 2014; Osterwalder et al., 2010, p. 27). Accessibility of products or services could be of the utmost importance (Osterwalder et al., 2010, p. 25). Furthermore, large-scale operations may consist of multiple locations, such as production plants and warehouses (Boshoff, 2014; Osterwalder et al., 2010, p. 35). Similar processes will be implemented at the various locations, which could possibly be distributed over a wide geographical area (Boshoff, 2014).

- Distributed / hybrid project teams (BI12): Certain industries necessitate team members involved in the same project to work from different locations (Boshoff, 2014; Osterwalder et al., 2010, p. 27). Team members of hybrid project teams work towards a common goal and work mostly virtually and only communicate in person occasionally (Bard, 2015, pp. 5-6).

- Low level of skills required / available (BI13): Semiskilled or unskilled employees, whose salaries or wages contribute to a lower cost base, will be employed for routine-based tasks in entities aiming for low payroll costs (Boshoff, 2014).

- Reduction of down time / reliability of systems (BI14): In the e-commerce environment system downtime can be detrimental to the success of the entity (Smit, 2009, p. 10). In other environments, such as retail or manufacturing entities, the systems needed for the operation of point-ofsale systems and manufacturing equipment are imperative to the success of an entity (Boshoff, 2014).

- Up-skilled workforce / decentralisation of authority (BI15): Employee morale is increased when employees are allowed to make decisions without supervision or approval from management, which decreases cycle time, improves 
flexibility in the process and increases the effectiveness and efficiency of processes (Drury, 2015, p. 14).

- Push or pull operations (BI16): According to Bowersox, Closs, Bixby Cooper and Bowersox (2013, p. 19) an anticipatory or push model requires of management to anticipate customers' demands and plan production accordingly. A pull model, otherwise referred to as a responsive model (Bowersox et al., 2013, p. 20), on the other hand, refers to an approach whereby the entity creates a desire for and interest in the products or services it delivers (Dowling, 2004, p. 266). The entity will then react on the demand from its customers by delivering its products or services (Dowling, 2004, p. 266).

- Work from anywhere (BI17): Certain industries require that its employees work from various locations. Therefore, employees have to be able to access and share information from various locations (Boshoff, 2014; Osterwalder et al., 2010, p. 27, 29).

- Collaboration / integration (BI18): Integrating unrelated applications in order to perform end-to-end business processes seamlessly (Boshoff, 2014; Osterwalder et al., 2010, p. 29), while limiting human intervention, will enable staff members to focus on core business activities (Kumar, Gupta, \& Kapur, 2015, p. 1).

- Ease of use (BI19): Processes and systems, like point-ofsale terminals in retail stores, need to be easy to use and/ or uniform across locations, e.g. in industries confronted with unskilled labour forces or entities with geographically distributed branches (Boshoff, 2014). E-commerce platforms also need to be user friendly, as customers should be able to navigate the platform without assistance from the entity itself (Goosen \& Rudman, 2013, p. 97).

- Self-service (BI20): Providing customers with the ability to help themselves, particularly when performing monotonous, unambiguous tasks, has become more popular than onsite service amongst consumers, as it is more convenient and customers feel more in control of the service they receive (Osterwalder et al., 2010, p. 29; Scherer, Wünderlich, \& Von Wangenheim, 2015, pp. 177-178). It can also increase productivity in an entity and save costs relating to service delivery (Scherer et al., 2015, pp. 177-178, 196).

- Automation (BI21): Automation and the utilisation of technologies such as big data and cognitive analytics will lead to less human intervention, which will increase the importance of decisions made by the few employees involved in the decision-making process (Chiou et al., 2016). Two of the benefits of automation identified by Chiou et al. (2016) are reduction in production costs and improved quality of products.

- Personal assistance (BI22): Certain entities rely on human interaction to assist its customers during or after sales transactions or the delivery of services (Osterwalder et al., 2010, p. 24). This interaction could take the form of, amongst other things, face-to-face interaction such as at a point-of-sale terminal, call centres or e-mails (Osterwalder et al., 2010, p. 29). In certain instances dedicated personal assistance is central to an entity's business model, for example assigning a private banker to a banking client (Osterwalder et al., 2010, p. 24).

- Reliability of information (BI23): Intellectual resources, including, amongst other things, customer databases and proprietary knowledge are becoming critical elements in certain entities' business models (Osterwalder et al., 2010, p. 35). Entities may be dependent on up-to-date and, in certain cases, real-time information to assist in its decision-making processes and operations (Boshoff, 2014). Investment entities, for example, cannot afford to base their investment decisions on outdated information, while online retailers need to update the availability of inventory items in order to adequately manage customers' expectations (Boshoff, 2014).

- Minimum staff compliment (BI24): A minimum staff compliment is needed in an environment where highly skilled employees are employed (Boshoff, 2014).

- Leverage skills (BI25): According to Humbert (2007, p. 6) knowledge is the most important asset and the driver of economic input in the information age. In an environment where knowledge sharing is of the utmost importance, skills and knowledge will have to be leveraged in order to operate as effectively and efficiently as possible (Boshoff, 2014). In addition to knowledge sharing amongst employees, certain entities rely on user communities to assist one another with problem solving and even co-creating content (Osterwalder et al., 2010, p. 29).

- High performance teams (BI26): According to Alexander (2018, p. 4845) the use of high performance teams is essential to the execution of complex project goals.

- Mobile access by customers (BI27): Entities need to provide customers with access to the entity's product and service information from their mobile devices (Boshoff, 2014).

- Added value, reliability and quality of products and services (BI28): Selling prices can be increased in return for exclusive products or services of superior quality (Boshoff, 2014; Osterwalder et al., 2010, p. 23, 24, 41).

- Managed processes (BI29): According to Hernaus, Vuksic and Stemberger (2016, pp. 173-174) business process management provides the necessary coordination between business processes and will lead to increased efficiency of the processes and increase the level of performance of an entity.

\section{Aligning the business imperatives with COBIT processes}

The business imperatives identified in the previous section were mapped against the purpose of the enabling processes and underlying governance practices of COBIT 5 in order to identify the business imperatives that will be enabled by the implementation of COBIT 5. These business imperatives can be used as both business objectives and objectives for the IT department and can therefore be used to bridge the IT gap. Twenty four of the twenty nine business imperatives are successfully aligned to COBIT 5 enabling processes as shown in Table 2-A1, included in 
Appendix 1. These COBIT processes, if implemented correctly by IT in order to achieve the objectives as intended by COBIT 5, will ensure the achievement of the business imperatives and the implementation of appropriate IT solutions and technology architecture. The business imperatives and COBIT 5 enabling processes can be used to inform the IT solution and architecture selection decisions. This could be further discussed in a second proposed research paper.

\section{Practical implication for management}

In order to understand the value of having a comprehensive list of business imperatives, triangulated against both the Business Model Canvas and COBIT enabling processes, according to which the technology architecture of an entity can be designed, it is necessary to discuss the practical implication of this research for management. Technology architecture is defined, for the purpose of this study, as the conceptual design of IT components, including the interrelationship between these components, and the principles and guidelines governing the design, which should be developed and maintained in order to achieve an entity's IT goals and, ultimately, the strategic goals of the entity (Boshoff, 2014; International Organization Of Standardization, 2011, p. 2; Op't Land, Proper, Waage, Cloo, \& Steghuis, 2009, p. 35; The Open Group, 2011).

In order for IT to support the business objectives associated with the business model of the entity, technology architecture must be designed in alignment with the key driving forces unique to the particular entity (i.e. business imperatives) (Boshoff, 2014). The business imperatives identified in this study are the key driving forces of an entity that also serve as objectives for the IT department. Information technology managers can therefore implement systems and technology using a particular architecture to achieve a particular business imperative (identified from the comprehensive list developed in this study) serving as both an IT and business objective.

\section{Designing IT architecture in line with business imperatives}

The implementation of the COBIT 5 enabling processes that govern IT systems and processes employed in an entity will ensure the achievement of the business imperatives as objectives for the IT department. This, in turn, will support the business objectives of an entity. Figure 3 illustrates the process to be followed by management in order to successfully achieve business-IT alignment at the technology architecture level.

Three steps could be employed:

1. The first step in utilising the business imperatives identified in this study as objectives for the IT department and designing the technology architecture in line with the business imperatives, is to identify the objectives relevant to the business goals and strategy of the entity. These will form the basis for identification of those business imperatives

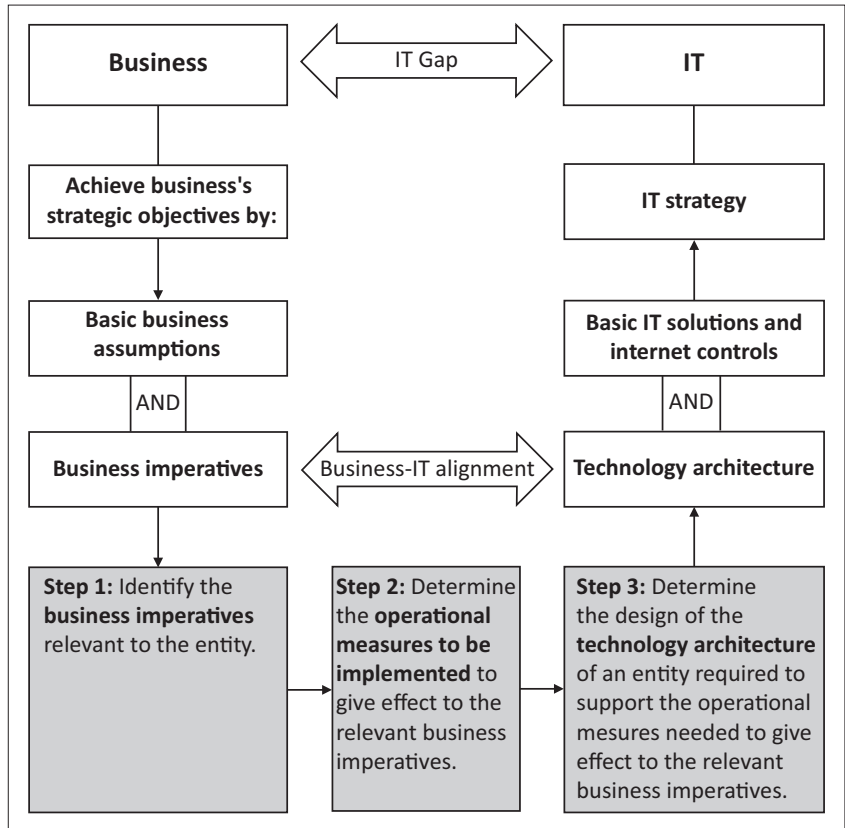

IT, information technology.

FIGURE 3: Steps to be followed by management in order to successfully achieve business information technology alignment.

relevant to the specific entity. According to Boshoff (2014), each entity should have a maximum of five to seven business imperatives. Senior management can use the twenty four business imperatives listed in this study to identify those business imperatives that serve as the key driving forces of their specific entity.

2. The second step is for senior management to determine the practical operational measures to be implemented from a business perspective to give effect to the business imperatives identified as key driving forces of their entity.

3. Once the operational business measures have been established, senior management and IT specialists can determine the impact on the technology architecture of the entity by assessing the manner in which IT can support these operational business measures (step 2) needed to give effect to the business imperatives identified by an entity. This process will ensure that the design of the technology architecture of the entity gives effect to its business imperatives and ultimately ensure alignment between a business's strategic objectives and their IT strategy in order to eliminate the IT Gap. (Boshoff, 2014).

\section{Evaluation of information technology architecture}

Alternatively, management can use the COBIT 5 enabling processes to evaluate whether their current IT architecture enables its business imperatives and supports its business objectives. This study showed that the COBIT 5 enabling processes support the achievement of the business imperatives listed in this study. Therefore, by assessing whether the COBIT 5 enabling processes are implemented in an entity, management can establish whether the design of the entity's IT architecture does in fact enable its business imperatives and support its business objectives. 


\section{Conclusion}

It is apparent from the findings of this study that effective communication between senior management and IT specialists is needed in order to successfully align the technology architecture with the business objectives of an entity (Bowen et al., 2007, p. 191; Goosen, 2012, pp. 14-15; Rudman, 2011, p. 37). However, it is also clear that miscommunication between senior management and IT specialists is a common occurrence and therefore the 'IT gap' (i.e. a gap between business and IT) is prevalent in most entities (Khan et al., 2016; Osterwalder, 2004, p. 16; Rudman, 2011, p. 37). It is important to have a tool or mechanism to convert the business objectives of an entity into objectives that can be understood by the IT department (Wu et al., 2015, p. 504).

From a theoretical perspective, this study adds to prior research relating to the alignment between IT and business objectives. Prior studies primarily focussed on adapting business models to incorporate rapidly evolving technology. This study focussed on the manner in which technology architecture can be designed in order to support the business objectives of an entity. A comprehensive list of business imperatives that can be used by senior management and IT specialists in an entity to ensure that the technology architecture of an entity can be designed with the objective of supporting these business imperatives in order to achieve alignment between the IT and business objectives of an entity was developed in this study. Furthermore, guidance was provided to management that can be used to evaluate whether its current IT architecture supports its business objectives.

Further guidance to design the technology architecture of an entity in line with its business imperatives, and ultimately its business objectives, by identifying the business imperatives relevant to an entity was provided to senior management and IT specialists. This was done by compiling a comprehensive list of business imperatives that act as the key driving forces of an entity and should be used as the basis to bridge the IT gap in order to ultimately achieve alignment between business and IT at the technology architecture level. Table 2-A1, included in Appendix 1, provides a list of twenty four business imperatives that can be used for this purpose.

The business imperatives which serve as both key driving forces of an entity and objectives for the IT department can act as a platform for discussion between senior management and IT specialists when designing or evaluating the technology architecture of an entity. This will ensure a shared understanding of the business objectives and the IT strategy between these two parties. Improved communication and the notion of working towards a common goal will reduce the IT gap and ensure business-IT alignment at a strategic level. Once the technology architecture has been designed in alignment with an entity's business objectives, IT specialists will be able to build, set-up, configure, operate and maintain the individual components of the technology architecture in such a manner that the IT gap will be bridged at an operational level (Boshoff, 2014).
An area for future research is to map the business imperatives identified in this study to the operational business measures and the impact on the IT architecture of an entity.

\section{Acknowledgements Competing interests}

The author declares that no competing interest exists.

\section{Author's contributions}

I declare that I am the sole author of this research article.

\section{Ethical consideration}

This article followed all ethical standards for carrying out research without direct contact with human or animal subjects.

\section{Funding information}

This research received no specific grant from any funding agency in the public, commercial or not-for-profit sectors.

\section{Data availability statement}

Data sharing is not applicable to this article as no new data were created or analysed in this study.

\section{Disclaimer}

The views expressed in this article are my own and not an official position of the University of Stellenbosch.

\section{References}

Alexander, E. (2018). Virtuoso project teams: Beyond high performance, a case study of the teaming success of the Motorola satellite communications system IRIDIUM" Program. 51st Hawaii International Conference on System Sciences. 03 January, Hawaii. Retrieved from https://scholarspace.manoa.hawaii.edu/bitstream/10125/50498/1/ paper0611.pdf

Bard, R. (2015). Strategies to achieve high performance in hybrid project teams: Addressing the relationship between Swedish project managers and Indian specialists at IBM Global Services. Unpublished master's thesis. Gothenburg: Chalmers University of Technology, 5-6. Retrieved from http://publications.lib. chalmers.se/records/fulltext/221870/221870.pdf

Bin-Abbas, H. \& Bakry, S.H. (2014). Assessment of IT governance in organizations: A simple integrated approach. Computers in Human Behavior, 32, 261-267. https://doi.org/10.1016/j.chb.2013.12.019

Bishop, W.A. (2018). A project management framework for small-and-medium-sized entities: Accounting software implementation. Journal of Economic and Financial Sciences, 11(1), 1-11. https://doi.org/10.4102/jef.v11i1.183

Boshoff, W. (2014). Computer Auditing 899 Class notes. Stellenbosch: Stellenbosch University.

Bowen, P.L., Cheung, M.Y.D. \& Rohde, F.H. (2007). Enhancing IT governance practices: A model and case study of an organization's efforts. International Journal of Accounting Information Systems, 8(3), 191-221. https://doi.org/10.1016/j.accinf.2007.07.002

Bowersox, D.J., Closs. D.J., Bixby Cooper, M. \& Bowersox, J.C. (2013). Supply Chain Logistics Management (4th edn.). New York, NY: Tim Vertovec, 19-20. Retrieved from https://www.inkling.com/read/supply-chain-logistics-management-bowersox4th/ supply-chain-logistics/copyright-information

Brown, C. (2012). Product centric versus customer centric. Retrieved from https:// blog.marketculture.com/2012/10/01/product-centric-versus-customer-centricdoes-it-matter/

Chesbrough, H. (2010). Business model innovation: Opportunities and barriers. Long range planning, 43(2-3), 354-363. https://doi.org/10.1016/j.Irp.2009.07.010

Chiou, B., Piazza, V., Nayak, B., Brown, C., Saddul, A., Ciabarra, C., Rice, R., ... Romero, D. (2016). 11 ways automation will change our lives. Retrieved from https://www. forbes.com/sites/forbestechcouncil/2016/05/27/eleven-ways-automation-willchange-our-lives/\#6b9fc0222436 
Clauss, T. (2017). Measuring business model innovation: Conceptualization, scale development, and proof of performance. R\&D Management, 47(3), 385-403. https://doi.org/10.1111/radm.12186

De Haes, S. \& Van Grembergen, W. (2009). An exploratory study into IT governance implementations and its impact on business/IT alignment. Information System Management, 26(2), 123-137. https://doi.org/10.1080/10580530902794786

De Haes, S., Van Grembergen, W. \& Debreceny, R.S. (2013). COBIT 5 and enterprise governance of information technology: Building blocks and research opportunities. Journal of Information Systems, 27(1), 307-324. https://doi.org/10.2308/isys-50422

Dowling, R.G. (2004). The art and science of marketing: Marketing for marketing managers (1st edn.). Oxford: Oxford University Press, 266. Retrieved from https:// books.google.co.za/books?id=DFduJaZ41MUC\&printsec=frontcover\&redir esc $=\mathrm{y} \# \mathrm{v}=$ onepage $\& q \& \mathrm{f}=\mathrm{false}$

Drury, C. (2015). Management and cost accounting (9th edn.). Andover: Andrew Ashwin, 13-14.

Enslin, Z. (2012). Cloud computing adoption: Control objectives for information and related technology (COBIT) - Mapped risk and risk mitigating controls. African related technology (COBIT) - Mapped risk and risk mitigating controls. African
Journal of Business Management, 6(37), 10185-10194. https://academicjournalsorg.ez.sun.ac.za/journal/AJBM/article-full-text-pdf/363FCF530555

Goosen, R. (2012). The development of an integrated framework in order to implement information technology governance principles at a strategic and operational level for medium-to-large sized South African businesses. Unpublished master's thesis. for medium-to-large sized South African businesses. Unpublished master's thesis. ac.za/handle/10019.1/20279

Goosen, R. \& Rudman, R. (2013). The development of an integrated framework in order to address King III's IT governance principles at a strategic level. South African Journal of Business Management, 44(4), 91-103. https://doi.org/10.4102/sajbm.v44i4.171

Hernaus, T., Vuksic, V.B. \& Stemberger, M.I. (2016). How to go from strategy to results? Institutionalising BPM governance within organisations. Business Process Management Journal, 22(1), 173-195. https://doi.org/10.1108/BPMJ-03-2015-0031

Humbert, M. (2007). Technology and workforce: Comparison between the information revolution and the industrial revolution, 6 . Retrieved from https://infoscience. epfl.ch/record/146804/files/InformationSchool.pdf

Institute of Directors Southern Africa. (2009). King III report on governance for South Africa, 83. Retrieved from https://cdn.ymaws.com/www.iodsa.co.za/resource/ resmgr/king_iii/King_Report_on_Governance_fo.pdf

Institute of Directors Southern Africa. (2016). King IV report on governance for South Africa, 62-63. Retrieved from https://cdn.ymaws.com/www.iodsa.co.za/resource/
collection/684B68A7-B768-465C-8214-E3A007F15A5A/IoDSA_King_IV_ collection/684B68A7-B768
Report_-_WebVersion.pdf

International Organization of Standardization. (2011). Systems and software engineering: Architecture description, 2. Retrieved from https://ieeexplore.iee. engineering: Architecture descrip
org/document/6129467/metrics

ISACA. (2013). Cobit5 toolkit - COBIT5-Governance-and-Management-PracticesActivities April2014. Retrieved from http://www.isaca.org/cobit/pages/default.aspx

IT Governance Institute (ITGI). (2003). Board briefing on IT governance (2nd edn.), 10 20. Retrieved from http://www.isaca.org/restricted/Documents/26904_Board Briefing_final.pdf

IT Governance Institute (ITGI). (2008). The Val IT Framework 2.0 Extract 32. Retrieved from http://www.isaca.org/Knowledge-Center/Val-IT-IT-Value-Delivery-/Documents/ VallT-Framework-2.0-Extract-Jul-2008.pdf

Joshi, A., Bollen, L., Hassink, H., De Haes, S. \& Van Grembergen, W. (2018). Explaining IT governance disclosure through the constructs of IT governance maturity and IT
strategic role. R\&D Management, 55(3), 368-380. https://doi.org/10.1016/j. strategic role.
im.2017.09.003

Juiz, C., Gómez, M. \& Barceló, M.I. (2012). Business/IT projects alignment through the project portfolio approval process as IT governance instrument. Procedia-Socia project portfolio approval process as IT governance instrument. Procedia-Social
and Behavioral Sciences, 65, 70-75. https://doi.org/10.1016/j.sbspro.2012.11.093

Juiz, C. \& Toomey, M. (2015). To govern IT, or not to govern IT? Communications of the ACM, 58(2), 58-64. https://doi.org/10.1145/2656385

Kark, K., White, M. \& Briggs, B. (2015). 2015 global ClO survey - Creating legacy, 53. Retrieved from http://www2.deloitte.com/content/dam/Deloitte/at/Documents/ technology-mediatelecommunications/cio-survey2015.pdf

Khan, N., Reynolds, J. \& Schrey, C. (2016). Partnering to shape the future - IT's new imperative. Retrieved from https://www.mckinsey.com/business-functions/ mckinsey-digital/our-insights/partnering-to-shape-the-future-its-new-imperative

Kim, S. (2012). Transitioning from fast-follower to innovator: The institutional foundations of the Korean telecommunications sector. Review of International Political Economy, 19(1), 140-168. https://doi.org/10.1080/09692290.2010.503125
Kumar, D., Gupta, V. \& Kapur, P.K. (2015). Assessment of quality factors in enterprise application integration. 4th International Conference on Reliability, Infocom Technologies and Optimization (ICRITO). 2-4 September, Noida, India. IEEE Society, 1. Retrieved from https://ieeexplore.ieee.org/abstract/document/7359352/

Kruger, W. (2012). Strategic business-IT alignment of application software packages: Bridging the information technology gap. South African Computer Journal, 49, 1-11. https://doi.org/10.18489/sacj.v49i0.90

Morales, J.C. (2014). 6 tips for implementing IT governance with COBIT 5. Retrieved from http://www.isaca.org/COBIT/focus/Pages/6-Tips-for-Implementing-IT-Governance With-COBIT-5.aspx

Op't Land, M., Proper, E., Waage, M., Cloo, J. \& Steghuis, C. (2009). Enterprise architecture (1st edn.). Berlin: Springer, 35.

Osterwalder, A. (2004). The Business Model Ontology - A proposition in a design science approach. Unpublished doctoral thesis. University of Lausanne, 14-16. Retrieved from http://www.hec.unil.ch/aosterwa/PhD/Osterwalder_PhD_BM_ Ontology.pdf

Osterwalder, A. \& Pigneur, Y. (2005). Clarifying Business Models: Origins, present, and future of the concept. Communications of the association for Information Systems, 15(1), 1-125. https://doi.org/10.17705/1CAIS.01601

Osterwalder, A., Pigneur, Y. \& Clark, T. (2010). Business Model Generation: A handbook for visionaries, game changers, and challengers (1st edn.) Amsterdam: Alexander Osterwalder \& Yves Pigneur, 15-41.

Osterwalder, A. \& Pigneur, Y. (2013). Designing Business Models and similar strategic objects: The contributions of IS. Journal of the Association for Information Systems, 14 (Special Issue, May 2013), 237-244. https://doi.org/10.17705/1jais.00333

Pulakos, E.D., Arad, S., Donovan, M.A. \& Plamondon, K.E. (2000). Adaptability in the workplace: Development of a taxonomy of adaptive performance. The Journal of Applied Psychology, 85(4), 612-624. https://doi.org/10.1037/0021-9010.85.4.612

Rajcoomar, A. (2017). A framework for the implementation and practice of professional bodies. Unpublished PhD dissertation. University of South Africa, Pretoria, 227.

Rudman, R.J. (2011). IT governance failure. Auditing SA, 37-39, Summer 2010/2011.

Sahd, L. \& Rudman, R.J. (2017). Best practices mobile technology risk assessment and control checklist. Southern African Journal of Accountability and Auditing Research, 19(1), 129-145.

Scherer, A., Wünderlich, N.V. \& Von Wangenheim, F. (2015). The value of self-service: Long-term effects of technology-based self-service usage on customer retention. MIS Quarterly, 39(1), 177-200. https://doi.org/10.25300/MISQ/2015/39.1.08

Schrage, M. (2015). Your customers' behavior is a competitive advantage. Retrieved from https://hbr.org/2015/01/your-customers-behavior-is-a-competitive-advantage

Seave, A. (2014). Fast followers not first movers are the real winners. Retrieved from https://www.forbes.com/sites/avaseave/2014/10/14/fast-followers-not-firstmovers-are-the-real-winners/\#89b45be314cc

Smit, S. (2009). Defining and reducing the IT gap by means of comprehensive alignment. Unpublished master's thesis. Stellenbosch: Stellenbosch University. Retrieved from http://scholar.sun.ac.za/handle/10019.1/15038

Spieth, P., Schneckenberg, D. \& Ricart, J.E. (2014). Business model innovation - State of the art and future challenges for the field. R\&D Management, 44(3), 237-247. https://doi.org/10.1111/radm.12071

Sylvester, A., Tate, M. \& Johnstone, D. (2011). Beyond synthesis: Re-presenting heterogeneous research literature. Behaviour \& Information Technology, 32(12), 1199-1215. https://doi.org/10.1080/0144929X.2011.624633

Teece, D.J. (2010). Business models, business strategy and innovation. Long Range Planning, 43(2-3), 172-194. https://doi.org/10.1016/j.Irp.2009.07.003

The Open Group. (2011). TOGAF 9.1. Retrieved from http://pubs.opengroup.org/ architecture/togaf9-doc/arch/index.html

West, D., Ford, J. \& Ibrahim, E. (2015). Strategic marketing: Creating competitive advantage (3rd edn.). Oxford: Oxford University Press, 152. Retrieved from https://books.google.co.za/books?id=CpueBwAAQBAJ\&printsec=frontcover\&sou $\mathrm{rce}=\mathrm{gbs} \_g e \_s u m m a r y \_r \& \mathrm{cad}=0 \# \mathrm{v}=$ onepage $\& \mathrm{q} \& \mathrm{f}=$ false

Wilkin, C.L. \& Chenhall, R.H. (2010). A review of IT governance: A taxonomy to inform accounting information systems. Journal of Information Systems, 24(2), 107-146. https://doi.org/10.2308/jis.2010.24.2.107

Wu, S., Straub, D.W. \& Liang, T. (2015). How information technology governance mechanisms and strategic alignment influence organizational performance: Insights from a matched survey of business and IT managers. MIS Quarterly, 39(2), 497-518. https://doi.org/10.25300/MISQ/2015/39.2.10 


\section{Appendix 1}

TABLE 1-A1: Conversion of the building blocks of the Business Model Canvas into business imperatives

\begin{tabular}{|c|c|c|}
\hline $\begin{array}{l}\text { Nine building blocks of the } \\
\text { Business Model Canvas }\end{array}$ & $\begin{array}{l}\text { Sub-categories of the building blocks, representing } \\
\text { generic business objectives }\end{array}$ & Building blocks converted into business imperatives \\
\hline 1. Customer segments & $\begin{array}{l}\text { - Mass market } \\
\text { - Mass market } \\
\text { - Niche market } \\
\text { - Segmented } \\
\text { - Diversified } \\
\text { - Multi-sided platforms }\end{array}$ & $\begin{array}{l}\text { High throughput (BI1) } \\
\text { Customer centric (BI2) }\end{array}$ \\
\hline 2. Value propositions & $\begin{array}{l}\text { - Price } \\
\text { - Cost reduction } \\
\text { - Accessibility } \\
\text { - Customisation } \\
\text { - 'Getting the job done' } \\
\text { - 'Getting the job done' } \\
\text { - All sub-categories } \\
\text { - Newness } \\
\text { - Newness } \\
\text { - 'Getting the job done' }\end{array}$ & $\begin{array}{l}\text { Low costs (BI3)† } \\
\text { Diverse products or lines of business (BI4) } \\
\text { Productivity and efficiency (BI5) } \\
\text { Reduction of delivery / cycle time (BI6) } \\
\text { Product centric (BI7) } \\
\text { Innovation (BI8) } \\
\text { Fast follower (BI9) } \\
\text { Rapid adaptability (BI10) }\end{array}$ \\
\hline 3. Channels & Various channel phases & Distributed branches and processes (BI11) \\
\hline
\end{tabular}

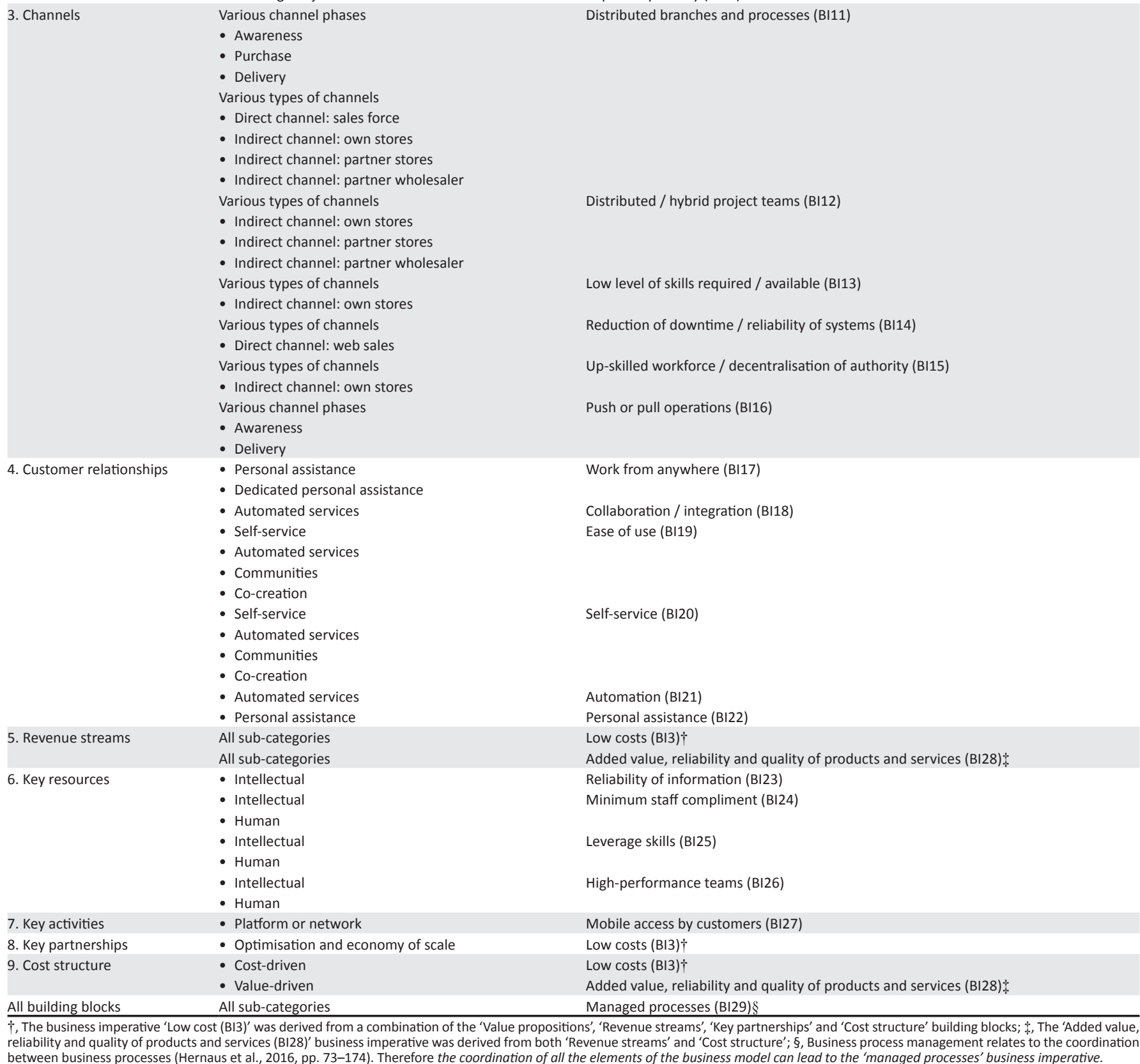




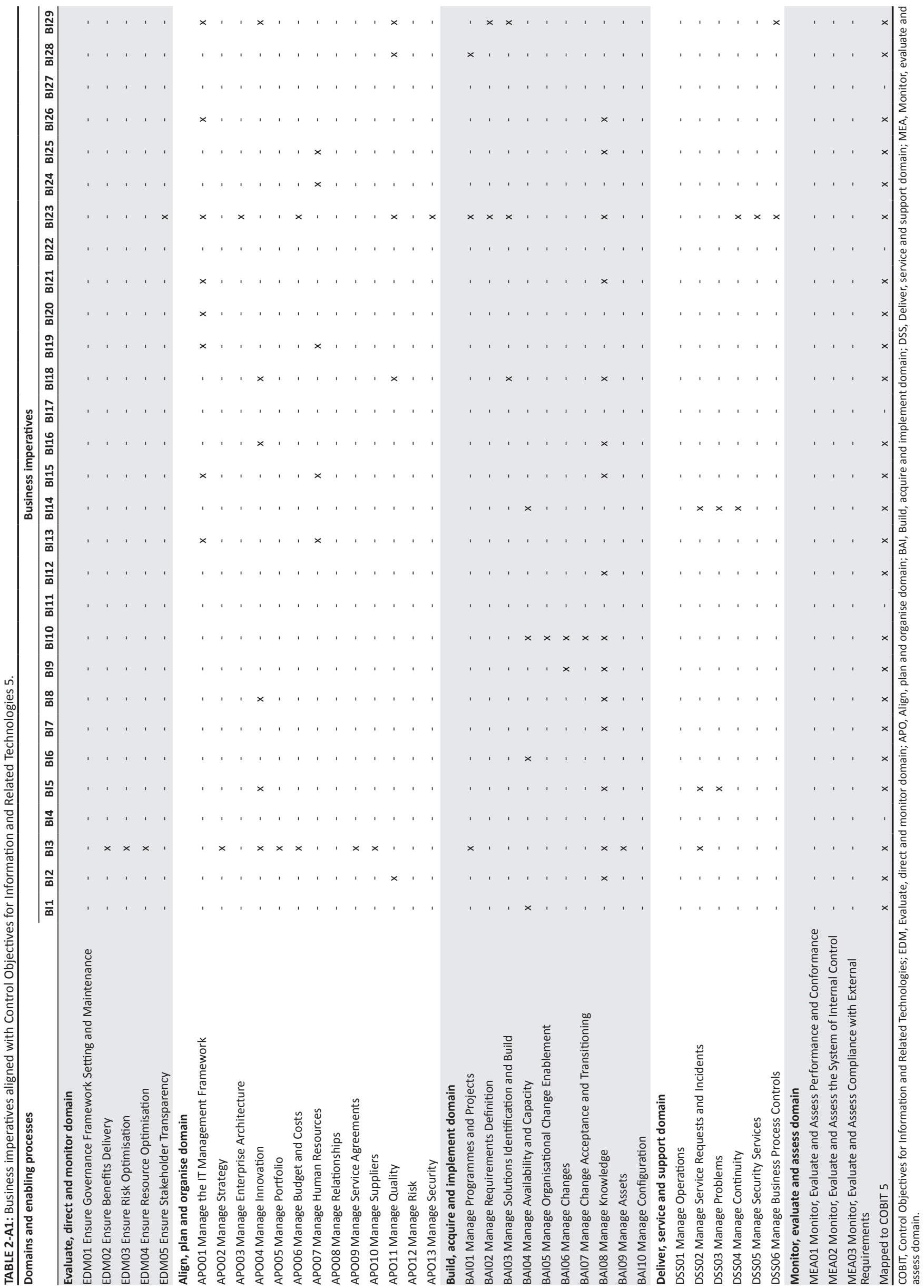

